\title{
La evaluación para el ingreso al servicio educativo y su impacto en el rendimiento de la prueba PISA en México
}

\author{
Juan Rubén Compañ García (D) \\ Gobierno del estado de México
}

Resumen. El presente artículo tiene como propósito caracterizar y analizar la política de ingreso al servicio docente implementada por la administración de gobierno (2012-2018) y el impacto que pudo tener en los resultados de PISA 2018 en lectura, matemáticas y ciencias. Se utilizó a la evaluación para el ingreso al servicio educativo como un canal de comunicación, cuya finalidad fue establecer un nuevo sistema de regulación en el sistema educativo nacional, dirigidos a atraer a los mejores docentes y elevar la calidad educativa. El estudio advierte que se presentó una tendencia hacia mejorar los niveles de rendimiento en los docentes que ingresan al servicio educativo, lo cual pudo tener un efecto positivo en los logros de aprendizaje de los y las estudiantes, así como debilidades en el proceso de implantación del nuevo sistema de regulación de ingreso al servicio educativo. Se concluye en el texto, que se necesitan dispositivos de política educativa que se les dé seguimiento en términos de evaluarlos y focalizarlos. La política educativa tiene que gozar de cierta estabilidad, coherencia, coordinación y buscar el bienestar general, si de verdad se aspira a la calidad educativa.

Palabras clave: calidad educativa; evaluación docente; PISA; política educativa.

A avaliação para admissão ao serviço educacional e seu impacto no desempenho da prova PISA no México

Resumo. O objetivo deste artigo é caracterizar e analisar as prioridades das políticas educacionais implementadas pela administração do governo (2012-2018) e associá-las ao impacto que o PISA poderia ter nos últimos resultados, em termos de acesso, equidade e qualidade de a educação. $A$ abordagem de prioridades é usada para estudar as seguintes prioridades de política educacional: 1) acesso à escola, 2) o Programa para Eliminar Atraso Educacional, o Programa de Escolas em Tempo Integral e o Programa de Inclusão e Alfabetização Digital e 3) a política de avaliação de professores. O estudo percebe, através das evidências, que algumas ações tiveram um efeito positivo nas realizações de aprendizagem dos alunos, bem como fragilidades consideráveis no processo de implementação de políticas educacionais. Há necessidade de dispositivos de políticas educacionais que sejam acompanhados em termos de avaliação e direcionamento deles. A política educacional deve gozar de certa estabilidade, coerência, coordenação e buscar o bem-estar geral, se realmente aspira à qualidade e à equidade da educação.

Palavras-chave: qualidade educacional; avaliação de professores; PISA; política educacional.

The assessment for the access to the education service and its impact on the performance of the PISA test in Mexico

Abstract. The purpose of this article is to characterize and analyze the educational policy priorities implemented by the government administration (2012-2018), and associate them with the impact that PISA could have on the latest results, in terms of access, equity and quality of The education. The priorities approach is used to study the following educational policy priorities: 1) access to school, 2) the Program to Eliminate Educational Lag, the Full-Time Schools Program and the Inclusion and Literacy Program Digital and 3) the teacher evaluation policy. The study realizes, through the evidence, that some actions had a positive effect on the learning achievements of the students, as well as considerable weaknesses in the process of implementing educational policies. There is a need for educational policy devices that are followed up in terms of evaluating and targeting them. The educational policy must enjoy a certain stability, coherence, coordination and seek general well-being, if it really aspires to educational quality and equity..

Keyword: educational quality, staff assessment, PISA, education policy. 


\section{Introducción}

El Programa para la Evaluación Internacional de Estudiantes (PISA, por sus siglas en inglés), es una evaluación que se realiza con la participación de países miembros de la OCDE (Organización para la Cooperación y el Desarrollo Económico) y otros que no lo son -el número de participación de países varía en cada aplicación-a jóvenes de 15 años de edad cada tres años. La prueba evalúa tres áreas: lenguaje, matemáticas y ciencias. De acuerdo al rendimiento de aprendizaje que obtienen los y las estudiantes, es que se les clasifica a los países por no tener un desempeño favorable o resaltar los logros. En el caso de México, los resultados en los logros de aprendizaje en las pruebas (2000, 2003, 2006, 2009, 2012, 2015 y 2018) lo ubican con un desempeño no favorable, que está por debajo del promedio de la OCDE en las tres áreas evaluadas (Backhoff, Bouzas, Contreras, Hernández y García, 2007; Santiago, Mc Gregor, Nushe, Ravela y Toledo, 2012; Martínez, 2017; INEE, 2016).

El rendimiento en los logros de aprendizaje que tienen los paíseslos resultados no se dan por escuela ni por alumno, sino sobre el sistema educativo en su conjunto-, se utiliza como referente importante para diseñar e implementar acciones de política pública por los responsables -no tanto de prácticas de enseñanza y aprendizaje-, con aras a mejorar los resultados y a hacer un buen uso de los mismos (Martínez, 2012). Contextualizar los resultados permite, entre otras cuestiones, considerar aspectos no cognitivos como el contexto familiar del alumno, entornos de aprendizaje, factores demográficos, sociales y económicos (OCDE, 2017; Martínez, 2016) además de diversas acciones de política educativa que impulsan las diferentes administraciones de los gobiernos en relación a mejorar los aprendizajes (Rivas, 2015; Muñoz, 2005).

Existen diversas investigaciones que consideran diferentes aspectos asociados a los aprendizajes, con la finalidad de comprender con mayores elementos, el bajo nivel de rendimiento que los y las estudiantes logran en las pruebas. En estos estudios encuentran que factores como lo social, económico, político y educativo, están fuertemente asociados al rendimiento (Blanco, 2012; Muñoz Izquierdo, 2009; Backhoff et al., 2007).

En ese tenor, el presente artículo tiene como propósito caracterizar y analizar la política de ingreso al servicio educativo implementada por la administración de gobierno (2012-2018) y el impacto que pudo tener en los últimos resultados de PISA. El artículo se integra por 5 apartados. El primero hace alusión al punto de referencia teórica, el cual se apoyará en los conceptos de canales de comunicación y dispositivos propuestos por Axel Rivas. El segundo habla, a modo de contextualizar, sobre algunos indicadores del sistema 
educativo nacional. El tercer apartado presenta los resultados obtenidos en la prueba PISA en lectura, matemáticas y ciencias. El cuarto apartado aborda la política de evaluación para el ingreso al servicio educativo impulsada por la administración de gobierno (2012-2018) y su relación con los logros de aprendizaje de PISA. EI quinto apartado cierra con los comentarios finales.

\section{Punto de referencia teórica: canales de comunicación y dispositivos}

La política educativa no se puede comprender de forma unidireccional, son prácticas de gobierno (Hunter, 1998; Rose, 1999) que interactúan de forma diversa y compleja a partir de sus actores e instituciones y que se modifican en sus diferentes niveles de gobierno (micro, meso y macro). Las prácticas de gobierno priorizan ciertas acciones y recursos, otras, no las consideran. Atienden a determinados sectores, otros, los excluyen (Rivas, 2015). Es importante evaluar las características de las políticas educativas más que su contenido formal (Scarstacini, Spiller y Stein, 2010; Rivas, 2015; Bernstein, 1998).

La política educativa utiliza diversos medios para materializarse en el conjunto del sistema educativo nacional, los canales de comunicación y los dispositivos, son un ejemplo. Los canales de comunicación "son mecanismos recurrentes con una lógica de intervención que establece niveles de coerción sobre actores e instituciones" (Rivas, 2015) que pueden ser impuestos sin mayor problema, o resistidos por diversos sectores (Pedró y Puig, 1998). Los canales de comunicación son sistemas que permiten establecer la comunicación entre el Estado y las instituciones educativas, con miras a atender la práctica educativa.

Rivas (2015) refiere que los canales de comunicación pueden ser de dos tipos: a) unos que funciona como arterias y b) otros que son más específicos. En el primero pueden ser: el diseño curricular; la distribución de materiales (en especial los libros de texto), la evaluación de los alumnos y los regímenes académicos, la supervisión escolar, la formación docente inicial y continua, la carrera docente y la normativa educativa. En el segundo: concursos de cargos específicos, planes de mejora, políticas compensatorias y programas institucionalizados específicos.

De acuerdo con Rivas (2015) los canales de comunicación pueden tener larga historia, como el acceso y la equidad en los sistemas educativos o pueden crearse de acuerdo a las necesidades de ese momento. El sistema 
de evaluación de la carrera docente que se propuso durante la reforma educativa del 2013 fue un canal de comunicación nuevo que reguló el sistema educativo nacional y que tuvo un impacto sustancial.

Los canales de comunicación de la política educativa, se convierten en dispositivos cuando producen un efecto de encauzamiento de las acciones del sistema educativo, regulan prácticas y generan cierto control de los resultados. Los dispositivos "son la conversión de esos canales en motores de regulación de las prácticas con una orientación definida hacia resultados concretos" (Rivas, 2015, p. 321). La finalidad de los dispositivos es aprovechar los canales de comunicación y convertirlos en sistemas de regulación dirigidos a resultados específicos.

Los dispositivos al tener cierto control de los resultados y una orientación de los mismos, evalúa los resultados de las políticas que implementa para identificar que escuelas son las que necesitan los recursos o servicios, hace un seguimiento puntual de cómo son recibidos y utilizados los recursos y puede delegar responsabilidades a distintos actores.

Los dispositivos pueden ser autoritarios o democráticos. Puede ser que el dispositivo sea muy centralizador, pero se base en las consultas sistémicas que reconozcan y redistribuyan las asimetrías sociales. 0 ser democrático y permita la participación de múltiples voces. Los dispositivos, pueden manipular conciencias o generar la capacidad de reflexión crítica y de compromiso social. Los dispositivos cambian la vida de las personas de forma masiva y sistemática (Rivas, 2015).

Una vez que se estableció el encuadre o el punto de referencia teórica, es momento de pasar al siguiente apartado, que abordará algunos indicadores del sistema educativo nacional, en relación a la población que atiende y a las oportunidades de acceso a la escuela en relación a la posición en la distribución del ingreso per cápita del hogar.

\section{Contexto mexicano}

El Sistema Educativo Mexicano, mantiene un crecimiento importante en la tasa neta de escolarización en la población de 12 a 17 años de edad, la cual estudia, la educación secundaria o media superior. Del año 2003 al año 2019, la mejora de los indicadores es notable (Gráfica 1). El sistema escolar pasó de tener una matrícula de 4858083 en secundaria (12-14 años) para 2003 a 5634455 en 2018, un incremento en la matrícula de 776 372. En media superior (15-17 años) se pasó de una matrícula de 2 
569650 en 2003 a 4233240 en 2018, lo que implicó un crecimiento de 1663590 en la matrícula, es decir, México tuvo una mayor proporción de jóvenes escolarizados (Backhoff, 2019).

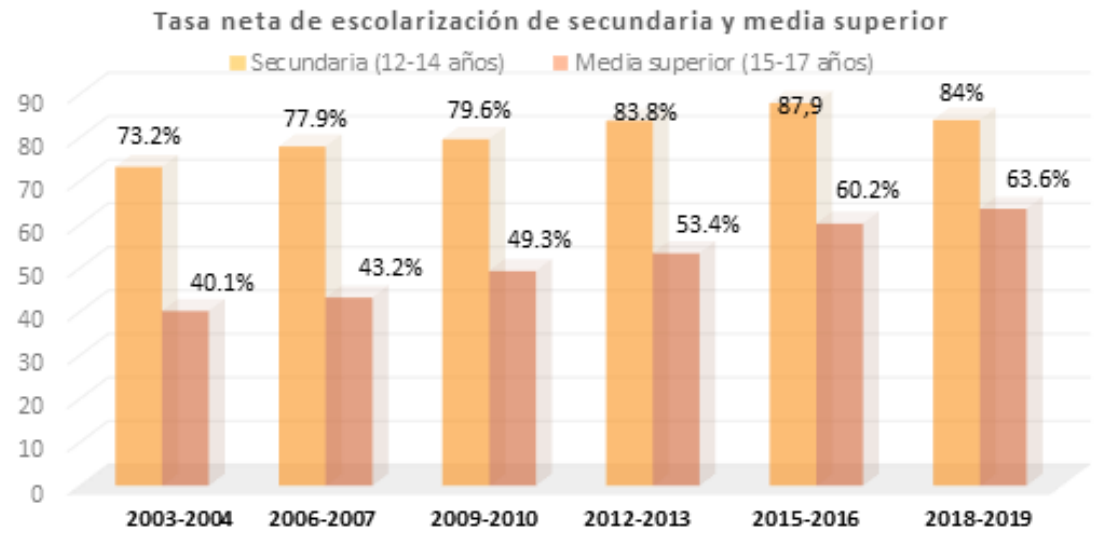

Gráfica 1. Tasa neta de escolarización en secundaria y media superior.

Fuente: SEP (2020).

Existe un importante avance en los indicadores en relación a la tasa neta de escolarización de los alumnos y alumnas en los niveles de secundaria y media superior, sin embargo, la igualdad de oportunidades educativas, no se desarrolla al mismo ritmo, pues las desigualdades aún son amplias. Aunque es importante referir, que hay avance en los indicadores (Gráfica 2).

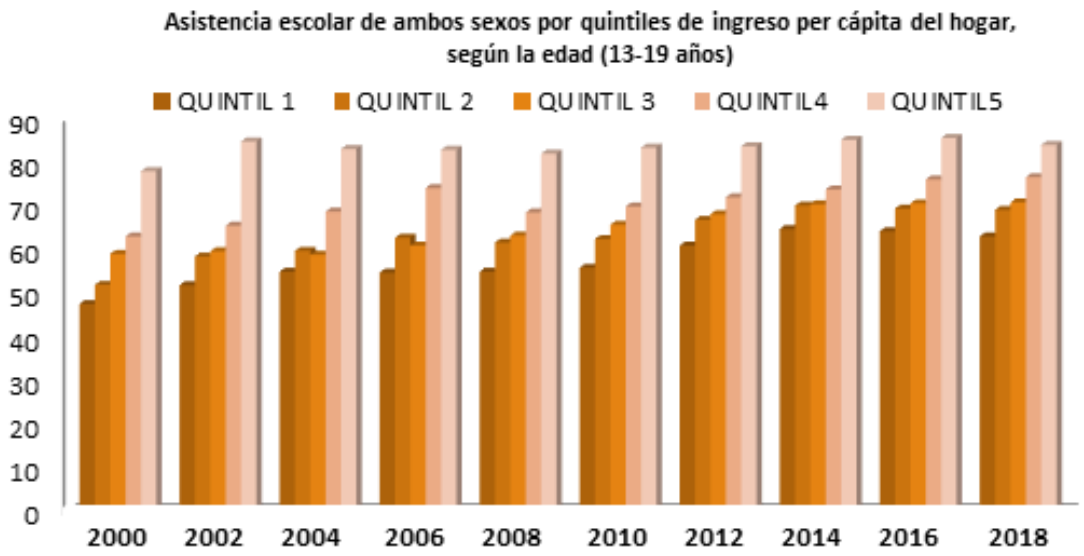

Gráfica 2. Asistencia escolar de ambos sexos por quintiles de ingreso per cápita del hogar, según la edad.

Fuente: CEPALSTAT (2020). 
La asistencia a la escuela de los sectores menos favorecidos, presenta un aumento importante. Para el año 2000 se tiene un $47.6 \%$ de asistencia escolar del quintil (el menos favorecido) para incrementar a $63.1 \%$ en el año 2018 , lo que equivale a un crecimiento de $15.5 \%$. La mejora de los indicadores van a la alza, aunque la asimetría de los niños y niñas de los hogares más pobres con respecto a los hogares con condiciones más favorables, todavía son amplias. Se tiene para el 2018, una asistencia escolar del quintil 5 (sector más favorecido) del $84.1 \%$ contra $63.1 \%$ del sector menos favorecido (quintil 1), lo que señala una diferencia de $21 \%$. Lo anterior advierte que mientras las oportunidades escolares para los niños y niñas de los hogares más pobres van en aumento, de manera paralela, la desigualdad entre sectores, continúa. Hay un acceso desigual a la escuela, que se relaciona de manera importante con la posición en la distribución de ingreso. Las oportunidades de acceso a la escuela no son equitativas, esto es lo que los datos muestran, a pesar de la mejora en los indicadores.

Una vez que se presentaron los indicadores en términos de la población que atiende el sistema educativo nacional y las oportunidades de acceso a la escuela en relación a la posición en la distribución del ingreso, es pertinente identificar los resultados de aprendizaje alcanzados por la población estudiantil, con la finalidad de tener una caracterización más amplia del sistema educativo nacional y, ello nos sirva como herramientas útiles para el posterior análisis.

\section{Resultados de PISA en México}

El Programa Internacional de Evaluación de Estudiantes (PISA, por sus siglas en inglés) mide la capacidad de los estudiantes de 15 años de edad para responder a los desafíos de la sociedad actual, que valora lo que las personas pueden hacer con lo que saben y no tanto lo que saben (OCDE, 2018). PISA examina si el alumno es capaz de aplicar su conocimiento a diversos contextos escolares y no escolares. Las evaluaciones de PISA se realizan cada tres años. Evalúan tres áreas de conocimiento: lectura, matemáticas y ciencias, basados en los marcos de PISA (OCDE, 2018) Cabe referir, que en cada aplicación de la prueba se enfatiza un área en específico. En el año 2000 (primera aplicación de la prueba) se concentró en la lectura; 2003, matemáticas y 2006 en ciencias, con ello se termina el primer ciclo. El segundo ciclo inicia en 2009 con lectura; 2012, matemáticas y 2015 ciencias. Para 2018, inicia el tercer ciclo de evaluación con el énfasis en lectura. 
PISA utiliza ocho niveles para captar la progresión de la dificultad de la competencia lectora, el nivel más alto es el seis y el más bajo es el 1c, cada uno con sus características. Para matemáticas y ciencias son 7 niveles, el nivel más alto es el 6 y el nivel más bajo es el que está por debajo del nivel 1 , como se muestra en la tabla 1 .

Tabla 1. Descripción de los niveles de competencia de lenguaje, matemáticas y ciencias.

\begin{tabular}{|c|c|c|c|}
\hline Nivel & Características Lectura & $\begin{array}{l}\text { Características } \\
\text { Matemáticas }\end{array}$ & Características Ciencias \\
\hline 6 & $\begin{array}{l}\text { Las tareas en este nivel } \\
\text { generalmente requieren } \\
\text { que el lector haga varias } \\
\text { inferencias, comparacio- } \\
\text { nes y contrastes que son a } \\
\text { lavez detalladosy precisos. } \\
\text { Requieren la demostración } \\
\text { de una comprensión com- } \\
\text { pleta y detallada de uno } \\
\text { o más textos y pueden } \\
\text { implicar la integración de } \\
\text { la información de más de } \\
\text { un texto. Las tareas pueden } \\
\text { requerir que el lector se } \\
\text { encuentre con ideas des- } \\
\text { conocidas, en presencia de } \\
\text { información destacada de } \\
\text { carácter similar, y que ge- } \\
\text { nere categorías abstractas } \\
\text { de interpretaciones. Las } \\
\text { tareas de reflexionar y eva- } \\
\text { luar pueden requerir que } \\
\text { el lector emita hipótesis } \\
\text { sobreo evalúecríticamente } \\
\text { un texto complejo sobre } \\
\text { un tema desconocido, } \\
\text { teniendo en cuenta varios } \\
\text { criterios o puntos de vista, } \\
\text { y que aplique comprensio- } \\
\text { nes sofisticadas más allá } \\
\text { del texto. Una condición } \\
\text { relevante para las tareas } \\
\text { de acceder y obtener en } \\
\text { este nivel es la precisión } \\
\text { del análisis y la atención al } \\
\text { detalle que es poco visible } \\
\text { en los textos. }\end{array}$ & $\begin{array}{l}\text { Los alumnos saben for- } \\
\text { mar conceptos, generali- } \\
\text { zar y utilizar información } \\
\text { basada en investigacio- } \\
\text { nes y modelos de situa- } \\
\text { ciones problemáticas } \\
\text { complejas, así comousar } \\
\text { sus conocimientos en } \\
\text { contextos relativamente } \\
\text { no habituales. Pueden } \\
\text { relacionar diferentes } \\
\text { fuentes de información } \\
\text { y representaciones y } \\
\text { traducirlas entre ellas } \\
\text { de manera flexible. Los } \\
\text { estudiantes de este nivel } \\
\text { poseen un pensamiento } \\
\text { y razonamiento mate- } \\
\text { mático avanzado. Estos } \\
\text { alumnos pueden aplicar } \\
\text { su entendimiento y com- } \\
\text { prensión, asícomosu do- } \\
\text { minio de las operaciones } \\
\text { y relaciones matemáticas } \\
\text { simbólicas y formales, } \\
\text { para desarrollar nuevos } \\
\text { enfoques y estrategias } \\
\text { para abordar situaciones } \\
\text { nuevas. Los alumnos } \\
\text { pertenecientes a este } \\
\text { nivel pueden reflexionar } \\
\text { sobre sus acciones y } \\
\text { formulary comunicarcon } \\
\text { exactitud sus acciones y } \\
\text { reflexiones relativasasus } \\
\text { descubrimientos, inter- } \\
\text { pretaciones, argumentos } \\
\text { y su adecuación a las } \\
\text { situaciones originales. }\end{array}$ & $\begin{array}{l}\text { Los estudiantes pueden } \\
\text { recurrir a ideas y concep- } \\
\text { tos científicos interrela- } \\
\text { cionados de las ciencias } \\
\text { físicas, de la vida y de la } \\
\text { Tierray el espacio yutilizar } \\
\text { sus conocimientos proce- } \\
\text { dimentales, epistémicos } \\
\text { y de contenidos para } \\
\text { presentar hipótesis expli- } \\
\text { cativas de fenómenos, he- } \\
\text { chosy procesos científicos } \\
\text { nuevos, o bien para hacer } \\
\text { predicciones. Al interpre- } \\
\text { tar datos y pruebas, son } \\
\text { capaces de diferenciar la } \\
\text { información relevante de } \\
\text { la irrelevante y recurrir a } \\
\text { conocimientos externos } \\
\text { al programa educativo } \\
\text { convencional. Pueden } \\
\text { distinguir los argumentos } \\
\text { que se basan en pruebas } \\
\text { y teorías científicas de } \\
\text { aquellos basados en otras } \\
\text { consideraciones. Los estu- } \\
\text { diantes de nivel } 6 \text { pueden } \\
\text { evaluar diseños enfren- } \\
\text { tados de experimentos } \\
\text { complejos, estudios de } \\
\text { campo o simulaciones, y } \\
\text { justificar sus elecciones. }\end{array}$ \\
\hline
\end{tabular}




\begin{tabular}{|c|c|c|c|}
\hline Nivel & Características Lectura & $\begin{array}{l}\text { Características } \\
\text { Matemáticas }\end{array}$ & Características Ciencias \\
\hline 5 & $\begin{array}{l}\text { Lastareas en estenivel que } \\
\text { implican la recuperación } \\
\text { de información requieren } \\
\text { que el lector localice y } \\
\text { organice varios fragmentos } \\
\text { de información profunda- } \\
\text { mente incrustada, dedu- } \\
\text { ciendo qué información } \\
\text { del texto es relevante. Las } \\
\text { tareas reflexivas requieren } \\
\text { una evaluación crítica o } \\
\text { una hipótesis, sobre la } \\
\text { base de un conocimiento } \\
\text { especializado. Las tareas } \\
\text { de interpretación y las de } \\
\text { reflexión requieren una } \\
\text { comprensión completa y } \\
\text { detallada de un texto cuyo } \\
\text { contenido o forma es des- } \\
\text { conocido. Para todos los } \\
\text { procesos de la lectura, las } \\
\text { tareas en este nivel suelen } \\
\text { implicar tratar con concep- } \\
\text { tos que son contrariosa las } \\
\text { expectativas. }\end{array}$ & $\begin{array}{l}\text { los alumnos saben desa- } \\
\text { rrollar modelos y trabajar } \\
\text { con ellos en situaciones } \\
\text { complejas, identificando } \\
\text { los condicionantes y es- } \\
\text { pecificando los supues- } \\
\text { tos. Pueden seleccionar, } \\
\text { comparar y evaluar es- } \\
\text { trategias adecuadas de } \\
\text { solución de problemas } \\
\text { para abordar problemas } \\
\text { complejos relativos a es- } \\
\text { tos modelos. Losalumnos } \\
\text { pertenecientes a este ni- } \\
\text { vel pueden trabajar estra- } \\
\text { tégicamente utilizando } \\
\text { habilidades de pensa- } \\
\text { miento y razonamiento } \\
\text { bien desarrolladas, así } \\
\text { como representaciones } \\
\text { adecuadamente relacio- } \\
\text { nadas, caracterizaciones } \\
\text { simbólicas y formales, e } \\
\text { intuiciones relativas a } \\
\text { estas situaciones. Pue- } \\
\text { den reflexionar sobre } \\
\text { sus acciones y formular } \\
\text { y comunicarsus interpre- } \\
\text { tacionesyrazonamientos }\end{array}$ & $\begin{array}{l}\text { los estudiantes pueden } \\
\text { utilizar ideas o concep- } \\
\text { tos científicos abstractos } \\
\text { para explicar fenómenos, } \\
\text { hechos y procesos más } \\
\text { complejos que les son } \\
\text { desconocidos y que inclu- } \\
\text { yen numerosas relaciones } \\
\text { causales. Son capaces } \\
\text { de aplicar conocimien- } \\
\text { tos epistémicos más so- } \\
\text { fisticados para evaluar } \\
\text { diseños alternativos y } \\
\text { experimentales, así como } \\
\text { justificar sus elecciones } \\
\text { y usar los conocimientos } \\
\text { teóricos para interpretar la } \\
\text { información o hacer pre- } \\
\text { dicciones. Los estudiantes } \\
\text { de nivel } 5 \text { pueden evaluar } \\
\text { los modos de explorar una } \\
\text { cuestión dada de manera } \\
\text { científica e identificar las } \\
\text { limitaciones de la inter- } \\
\text { pretación de los conjuntos } \\
\text { de datos, incluyendo las } \\
\text { fuentes y los efectos de } \\
\text { la incertidumbre en los } \\
\text { datos científicos. }\end{array}$ \\
\hline
\end{tabular}




\begin{tabular}{|c|c|c|c|}
\hline Nivel & Características Lectura & $\begin{array}{l}\text { Características } \\
\text { Matemáticas }\end{array}$ & Características Ciencias \\
\hline 4 & $\begin{array}{l}\text { Las tareas en este nivel } \\
\text { que implican recuperar } \\
\text { información requieren } \\
\text { que el lector localice y } \\
\text { organice varios fragmentos } \\
\text { de información incrustada. } \\
\text { Algunas tareasen estenivel } \\
\text { requieren interpretar el } \\
\text { significado de matices del } \\
\text { lenguaje en una sección de } \\
\text { texto, teniendo en cuenta } \\
\text { el texto en su conjunto. } \\
\text { Otras tareas interpretativas } \\
\text { requieren comprender y } \\
\text { aplicar categorías en un } \\
\text { contexto desconocido. Las } \\
\text { tareas reflexivas en este } \\
\text { nivel requieren que los } \\
\text { lectores utilicen el cono- } \\
\text { cimiento formal o público } \\
\text { para emitir hipótesis sobre } \\
\text { o evaluar críticamente un } \\
\text { texto. Los lectores deben } \\
\text { demostrar una compren- } \\
\text { sión exacta de los textos } \\
\text { largos o complejos cuyo } \\
\text { contenido o forma puede } \\
\text { ser desconocido. }\end{array}$ & $\begin{array}{l}\text { Los alumnos pueden } \\
\text { trabajar con eficacia con } \\
\text { modelos explícitos en } \\
\text { situaciones complejas } \\
\text { y concretas que pueden } \\
\text { conllevar condicionantes } \\
\text { o exigir la formulación } \\
\text { de supuestos. Pueden } \\
\text { seleccionar e integrar } \\
\text { diferentes representa- } \\
\text { ciones, incluidas las } \\
\text { simbólicas, asociándolas } \\
\text { directamente a situacio- } \\
\text { nes del mundo real. Los } \\
\text { alumnos de este nivel } \\
\text { saben utilizar su gama } \\
\text { limitada de habilidades } \\
\text { y razonar con cierta pers- } \\
\text { picacia en contextos sen- } \\
\text { cillos. Pueden elaborar y } \\
\text { comunicar explicaciones } \\
\text { y argumentos basados } \\
\text { en sus interpretaciones, } \\
\text { argumentos y acciones. }\end{array}$ & $\begin{array}{l}\text { los estudiantes pueden } \\
\text { utilizar conocimientos } \\
\text { de contenidos más com- } \\
\text { plejos o abstractos, que } \\
\text { pueden dárseles o ser } \\
\text { recordados, para elaborar } \\
\text { explicaciones de hechos y } \\
\text { procesos más complejos o } \\
\text { menos conocidos. Pueden } \\
\text { ejecutar experimentos } \\
\text { que incluyan dos o más } \\
\text { variables independientes } \\
\text { en un contexto limitado. } \\
\text { Son capaces de justificar } \\
\text { un diseño experimental } \\
\text { recurriendo a elementos } \\
\text { del conocimiento proce- } \\
\text { dimental y epistémico. } \\
\text { Los estudiantes de nivel } \\
4 \text { pueden interpretar los } \\
\text { datos obtenidos de un } \\
\text { conjunto de datos mode- } \\
\text { radamente complejos o de } \\
\text { un contexto menos fami- } \\
\text { liar, extraer conclusiones } \\
\text { apropiadas que vayan más } \\
\text { allá de los datosy justificar } \\
\text { sus elecciones. }\end{array}$ \\
\hline
\end{tabular}




\begin{tabular}{|c|c|c|c|}
\hline Nivel & Características Lectura & $\begin{array}{l}\text { Características } \\
\text { Matemáticas }\end{array}$ & Características Ciencias \\
\hline 3 & $\begin{array}{l}\text { Las tareas en este nivel } \\
\text { requieren que el lector } \\
\text { localice, y enalgunos casos } \\
\text { reconozca la relación entre } \\
\text { varios fragmentos de infor- } \\
\text { mación que deben cumplir } \\
\text { varias condiciones. Las } \\
\text { tareas de interpretación } \\
\text { de este nivel requieren } \\
\text { que el lector integre varias } \\
\text { partes de un texto con el } \\
\text { fin de identificar una idea } \\
\text { principal, comprender una } \\
\text { relación o interpretar el } \\
\text { significado de una palabra } \\
\text { o frase. Tienen que tener } \\
\text { en cuenta muchas ca- } \\
\text { racterísticas al comparar, } \\
\text { contrastar o categorizar. } \\
\text { A menudo, la información } \\
\text { requerida no es prominente } \\
\text { o hay mucha información } \\
\text { de carácter similar; o bien } \\
\text { hay otros obstáculos en el } \\
\text { texto, como ideas que son } \\
\text { contrarias a lo esperado o } \\
\text { negativamente redactadas. } \\
\text { Lastareas reflexivasen este } \\
\text { nivel pueden requerir co- } \\
\text { nexiones, comparaciones } \\
\text { y explicaciones, o pueden } \\
\text { requerir que el lector } \\
\text { evalúe una característica } \\
\text { del texto. Algunas tareas } \\
\text { reflexivas requieren que } \\
\text { los lectores demuestren } \\
\text { una buena comprensión } \\
\text { del texto en relación con el } \\
\text { conocimiento familiar, de } \\
\text { cada día. Otras tareas no } \\
\text { requieren la comprensión } \\
\text { de textos detallados, pero } \\
\text { requieren que el lector } \\
\text { recurra al conocimiento } \\
\text { menos común. }\end{array}$ & $\begin{array}{l}\text { Los alumnos saben eje- } \\
\text { cutar procedimientos } \\
\text { descritos con claridad, } \\
\text { incluyendo aquellos que } \\
\text { requieren decisiones } \\
\text { secuenciales. Sus in- } \\
\text { terpretaciones son lo } \\
\text { bastante sólidas para } \\
\text { fundamentar la creación } \\
\text { de un modelo sencillo o } \\
\text { paraseleccionaryaplicar } \\
\text { estrategias de solución } \\
\text { de problemas sencillos. } \\
\text { Los alumnos de este } \\
\text { nivel saben interpretar y } \\
\text { utilizar representaciones } \\
\text { basadas en diferentes } \\
\text { fuentes de información } \\
\text { y razonar directamente a } \\
\text { partir de ellas. Muestran } \\
\text { cierta capacidad para } \\
\text { manejar porcentajes, } \\
\text { fracciones y números } \\
\text { decimales, así como } \\
\text { para trabajar con rela- } \\
\text { ciones proporcionales. } \\
\text { Sus soluciones reflejan } \\
\text { que pueden desarrollar } \\
\text { una interpretación y un } \\
\text { razonamiento básicos. }\end{array}$ & $\begin{array}{l}\text { Los estudiantes pueden } \\
\text { recurrir a conocimientos } \\
\text { de contenido moderada- } \\
\text { mente complejos para } \\
\text { identificaroelaborar expli- } \\
\text { caciones para fenómenos } \\
\text { conocidos. En situaciones } \\
\text { menos conocidas o más } \\
\text { complejas, pueden ela- } \\
\text { borar explicaciones si se } \\
\text { les da la base o la ayuda } \\
\text { correspondiente. Pue- } \\
\text { den recurrir a elementos } \\
\text { de sus conocimientos } \\
\text { procedimentales o epis- } \\
\text { témicos para realizar un } \\
\text { experimento simple en } \\
\text { un contexto limitado. Los } \\
\text { estudiantes de nivel } 3 \\
\text { son capaces de distinguir } \\
\text { las cuestiones científicas } \\
\text { de las no científicas e } \\
\text { identificar las pruebasque } \\
\text { respaldan una afirmación } \\
\text { científica. }\end{array}$ \\
\hline
\end{tabular}




\begin{tabular}{|c|c|c|c|}
\hline Nivel & Características Lectura & $\begin{array}{c}\text { Características } \\
\text { Matemáticas }\end{array}$ & Características Ciencias \\
\hline 2 & $\begin{array}{l}\text { Algunastareas en este nivel } \\
\text { requieren que el lector } \\
\text { localice uno o más frag- } \\
\text { mentos de información, } \\
\text { que pueden necesitar ser } \\
\text { deducidos y pueden tener } \\
\text { que cumplir una serie de } \\
\text { condiciones. Otras requie- } \\
\text { ren el reconocimiento de la } \\
\text { idea principal de un texto, } \\
\text { la comprensión de las re- } \\
\text { laciones, o interpretar su } \\
\text { significado dentro de una } \\
\text { parte limitada del texto } \\
\text { cuando la información no } \\
\text { es prominente y el lector } \\
\text { debe hacer inferencias de } \\
\text { bajo nivel. Las tareas en } \\
\text { este nivel pueden incluir } \\
\text { comparaciones o contras- } \\
\text { tes en base a una sola } \\
\text { característica en el texto. } \\
\text { Lastareas reflexivastípicas } \\
\text { en este nivel requieren } \\
\text { que los lectores hagan } \\
\text { una comparación o varias } \\
\text { conexiones entre el texto y } \\
\text { el conocimiento exterior, y } \\
\text { hagan uso de la experiencia } \\
\text { y las actitudes personales. }\end{array}$ & $\begin{array}{l}\text { Los alumnos saben in- } \\
\text { terpretar y reconocer } \\
\text { situaciones en contextos } \\
\text { que solo requieren una } \\
\text { inferencia directa. Los } \\
\text { alumnos de este nivel } \\
\text { pueden extraer informa- } \\
\text { ción de una única fuente } \\
\text { y usar un único modo } \\
\text { de representación. Los } \\
\text { estudiantes pueden uti- } \\
\text { lizar algoritmos básicos, } \\
\text { fórmulas, procedimien- } \\
\text { tos o convenciones para } \\
\text { resolver problemas que } \\
\text { contengan númerosente- } \\
\text { ros. Son capaces de hacer } \\
\text { interpretaciones literales } \\
\text { de los resultados. }\end{array}$ & $\begin{array}{l}\text { Los estudiantes son ca- } \\
\text { paces de recurrir a cono- } \\
\text { cimientos del día a día y } \\
\text { a conocimientos proce- } \\
\text { dimentales básicos para } \\
\text { identificar una explicación } \\
\text { científica adecuada, inter- } \\
\text { pretar datos e identificar } \\
\text { la cuestión de que se trata } \\
\text { en un diseño experimental } \\
\text { simple. Pueden utilizar } \\
\text { conocimientos científi- } \\
\text { cos básicos o del día a } \\
\text { día para identificar una } \\
\text { conclusión válida de un } \\
\text { conjunto de datos simple. } \\
\text { Los estudiantes de nivel } 2 \\
\text { muestran conocimientos } \\
\text { epistémicos básicos al po- } \\
\text { der identificar cuestiones } \\
\text { que podrían investigarse } \\
\text { científicamente. }\end{array}$ \\
\hline 1 & & $\begin{array}{l}\text { Los estudiantes son ca- } \\
\text { paces de contestar pre- } \\
\text { guntas que impliquen } \\
\text { contextosfamiliares don- } \\
\text { de toda la información } \\
\text { relevante esté presente } \\
\text { y las preguntas estén } \\
\text { claramente definidas. } \\
\text { Son capaces de identi- } \\
\text { ficar información y de- } \\
\text { sarrollar procedimientos } \\
\text { rutinarios conforme a } \\
\text { instrucciones directas } \\
\text { en situaciones explícitas. } \\
\text { Pueden llevar a cabo ac- } \\
\text { ciones que sean obvias y } \\
\text { seguirlas inmediatamen- } \\
\text { tea partir de un estímulo. }\end{array}$ & $\begin{array}{l}\text { Los estudiantes tienen un } \\
\text { conocimiento científico } \\
\text { tan limitado que sólo se } \\
\text { puede aplicar a pocas } \\
\text { situaciones que conocen. } \\
\text { Dan explicaciones cientí- } \\
\text { ficas obvias y parten de } \\
\text { evidencia explícita. }\end{array}$ \\
\hline
\end{tabular}




\begin{tabular}{|c|c|c|c|}
\hline Nivel & Características Lectura & $\begin{array}{c}\text { Características } \\
\text { Matemáticas }\end{array}$ & Características Ciencias \\
\hline $1 \mathrm{a}$ & $\begin{array}{l}\text { Las tareas en este nivel } \\
\text { requieren que el lector } \\
\text { localice una o más piezas } \\
\text { independientes de infor- } \\
\text { mación explícita; para } \\
\text { reconocer el tema principal } \\
\text { o el propósito del autor en } \\
\text { un texto sobre un tema } \\
\text { conocido, o para hacer } \\
\text { una conexión simple entre } \\
\text { la información del texto y } \\
\text { el conocimiento común, } \\
\text { de todos los días. Nor- } \\
\text { malmente, la información } \\
\text { requerida en el texto es } \\
\text { prominente y hay poca, o } \\
\text { ninguna, información de } \\
\text { carácter similar. El lector } \\
\text { es explícitamente dirigido } \\
\text { a considerar los factores } \\
\text { relevantes en la tarea y en } \\
\text { el texto. }\end{array}$ & & \\
\hline 248 & $\begin{array}{l}\text { Las tareas en este nivel } \\
\text { requieren que el lector } \\
\text { busque un único fragmento } \\
\text { de información explícita } \\
\text { en una posición promi- } \\
\text { nente en un texto breve } \\
\text { y sintácticamente simple } \\
\text { con un contexto y tipo de } \\
\text { texto familiar, como una } \\
\text { narración o una simple } \\
\text { lista. El texto normalmente } \\
\text { proporciona apoyoal lector, } \\
\text { como la repetición de la } \\
\text { información, imágenes } \\
\text { o símbolos conocidos. } \\
\text { Hay poca información } \\
\text { de carácter similar. En } \\
\text { las tareas que requieren } \\
\text { interpretación el lector } \\
\text { puede tener que realizar } \\
\text { conexiones simples entre } \\
\text { piezas adyacentes de in- } \\
\text { formación. }\end{array}$ & & \\
\hline
\end{tabular}




\begin{tabular}{|c|c|c|c|}
\hline Nivel & Características Lectura & $\begin{array}{c}\text { Características } \\
\text { Matemáticas }\end{array}$ & Características Ciencias \\
\hline 1c & $\begin{array}{l}\text { En este nivel, las tareas exi- } \\
\text { gen al lector comprender } \\
\text { el significado de palabras } \\
\text { escritas individualmente y } \\
\text { frases cortas. En las tareas } \\
\text { se pide a los estudiantes } \\
\text { que encuentren palabras o } \\
\text { frases en una lista o un tex- } \\
\text { to breves, que reconozcan } \\
\text { la forma impresa de objetos } \\
\text { yconceptos comuneso que } \\
\text { extraigan el significado } \\
\text { literal de frases sueltas } \\
\text { y pasajes muy breves y } \\
\text { sintácticamente sencillos } \\
\text { en contextos familiares. } \\
\text { Los textos ayudan a los es- } \\
\text { tudiantes con indicadores } \\
\text { explícitos, con repeticio- } \\
\text { nes, imágenes o símbolos } \\
\text { familiares y limitando los } \\
\text { datos similares. }\end{array}$ & & \\
\hline $\begin{array}{l}\text { Por de- } \\
\text { bajo del } \\
\text { nivel } 1\end{array}$ & & $\begin{array}{l}\text { Se trata de estudiantes } \\
\text { que no son capaces de } \\
\text { realizar las tareas de } \\
\text { matemáticas más ele- } \\
\text { mentales que pide PISA. }\end{array}$ & $\begin{array}{l}\text { Se trata de estudiantes } \\
\text { que no son capaces de } \\
\text { realizar las tareas de } \\
\text { ciencias más elementales } \\
\text { que pide PISA. }\end{array}$ \\
\hline
\end{tabular}

Fuente: OCDE (2018).

La prueba PISA no sólo evalúa los conocimientos y las habilidades de los estudiantes, también aplica una serie de cuestionarios a diferentes actores de la educación, con la finalidad de contextualizar los resultados de las pruebas y evitar interpretaciones reduccionistas (OCDE, 2017). Los aprendizajes alcanzados en PISA a lo largo de estos 18 años de aplicación en México en las tres áreas evaluadas (es importante referir que México ha participado en todas las pruebas), se muestran en la gráfica 3. Es importante referir que en este momento se presentan solo los puntaje- promedio alcanzados en cada una de las áreas, pero en líneas siguientes los resultados se contextualizaran tomando como elementos los canales de comunicación o los dispositivos que se utilizaron en la administración de gobierno (2012-2018) para la mejora de los aprendizajes. 


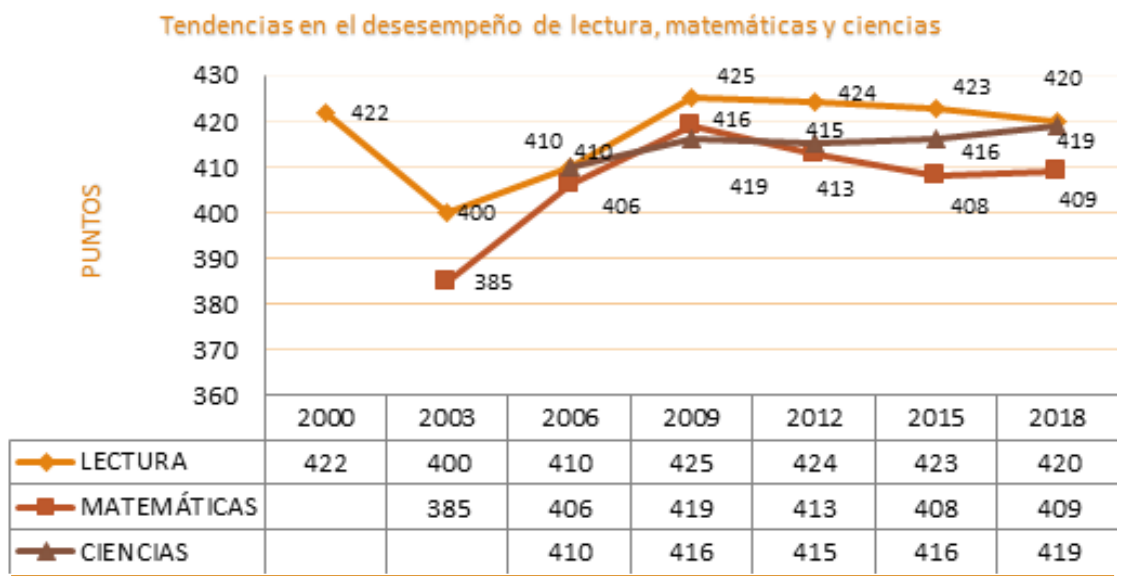

Gráfica 3. Tendencias en el desempeño de lectura, matemáticas y ciencias. Fuente: OCDE (2019).

Hasta el momento, lo que se puede percibir de acuerdo a los indicadores, es que los resultados de aprendizaje en las tres áreas evaluadas por PISA (lectura, matemáticas y ciencias) no existen diferencias importantes ni para mejorar ni posicionarse mejor. La lectura que se tiene de México ante estos resultados, es que los logros de aprendizaje son bajos. Los indicadores muestran que los puntajes obtenidos en 2003 son significativamente inferiores (lectura y matemáticas) con respecto a los puntos obtenidos en 2018. Cabe señalar que en 2003 hubo una participación de 41 países. Con una tendencia al incremento, en 2018 participaron 79 países. La tendencia de los resultados en la aplicación de la prueba PISA en los otros años, no muestra una diferencia importante en relación a la aplicación de 2018 (OCDE, 2019). Sin embargo, las interpretaciones de los resultados PISA han sido diferentes a lo largo de los años; por ejemplo, los resultados PISA 2003 eran una oportunidad para las políticas públicas (Muñoz, 2005; Rodríguez, 2005), a transitar a: en México no hay avances ni en lectura, matemáticas y ciencias (Poy, 2016) hasta referir, con PISA 2018, que ninguna administración de gobierno es la responsable de los resultados (Backhoff, 2019).

De acuerdo a los resultados en las tres áreas evaluadas (lenguaje, matemáticas y ciencias) en PISA 2018 y en comparación con el promedio OCDE (OCDE, 2019), un porcentaje muy bajo alcanza los niveles más altos ( 5 y 6 ). En el caso de lectura se tiene $0.7 \%$ en el nivel 5 y nulo en el nivel 6 (véase gráfica 4). En matemáticas tenemos $0.5 \%$ en el nivel 5 y nulo en el nivel 6 (véase gráfica 5 ). Para ciencias hay $0.3 \%$ en el nivel 5 y nulo en el nivel 6 (véase gráfica 6). 


\section{a) Resultados de PISA 2018 en Lectura}

En cuanto a los niveles de desempeño más bajos, se puede observar que en el área de lectura, el 60\% de estudiantes se concentró entre el nivel 1 y nivel 2 (gráfica 4). Con ello, se dice que los alumnos son capaces de identificar la idea principal de un texto, reconoce el propósito del autor en un texto, reflexiona sobre la forma de los textos cuando se les indica que lo hagan, tiene la capacidad de encontrar información en los textos. Y casi el $1 \%$ (nivel 5) puede discriminar entre un hecho y una opinión, diferenciar conceptos abstractos y contra intuitivos y comprender textos largos (OCDE, 2019).

En el nivel 3 y 4 de lectura concentra alrededor de $21 \%$ de estudiantes (gráfica 4). Lo anterior nos señala que los evaluados y evaluadas pueden ubicar fragmentos múltiples de información, vincular distintas partes de un texto, relacionar los textos con situaciones cotidianas, interpretar información y significados a partir del uso de lenguaje, evaluar críticamente un texto (OCDE, 2019).

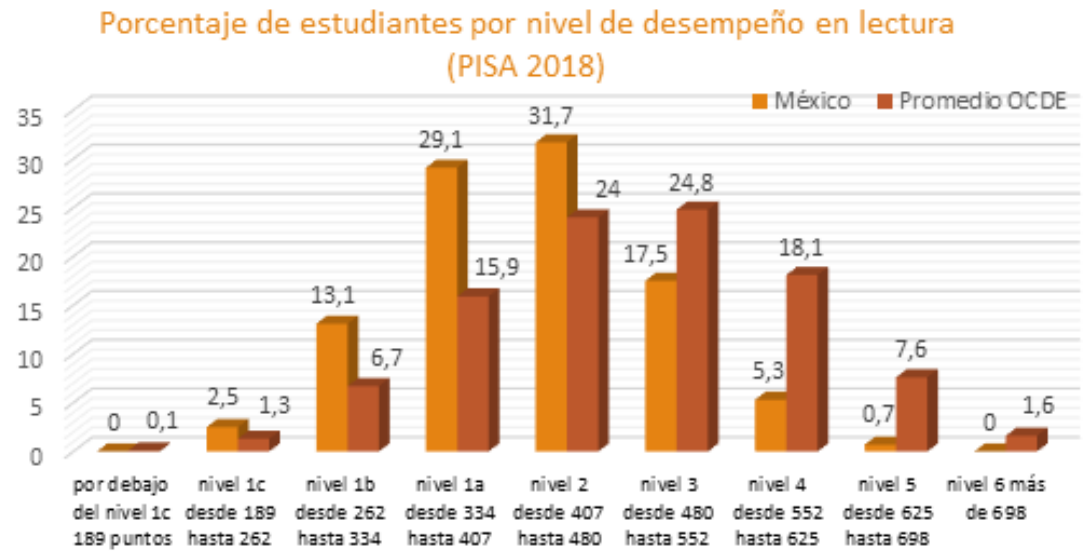

Gráfica 4. Porcentaje de estudiantes por nivel de desempeño en lectura.

Fuente: OCDE (2019).

\section{b) Resultados de PISA 2018 en matemáticas}

En matemáticas $26 \%$ de los evaluados y evaluadas están por debajo del nivel 1 y el 56\% se concentró entre el nivel 1 y nivel 2 (gráfica 5). Lo que implica que los y las alumnas (que alcanzan nivel 2) pueden reconocer e interpretar situaciones en contextos que requieren la inferencia directa, pueden identificar la información y realizar procedimientos rutinarios, hacen uso de un modo específico de elaborar las representaciones. El 0.5\% 
de estudiantes (nivel 5) puede seleccionar, comparar y evaluar estrategias pertinentes de solución para tratar un problema complejo, puede razonar sus acciones y comunicar sus argumentos (OCDE, 2019).

En matemáticas el nivel 3 y 4 concentra alrededor del 17\% de estudiantes (gráfica 5). En estos niveles los estudiantes son capaces de ejecutar procedimientos descritos claramente, seleccionan y aplican estrategias simples para solucionar un problema, pueden interpretar y usar representaciones basadas en diferentes fuentes de información, pueden explicar y construir argumentos, pueden razonar flexiblemente con cierta comprensión (OCDE, 2019).

Porcentaje de estudiantes por nivel de desempeño en

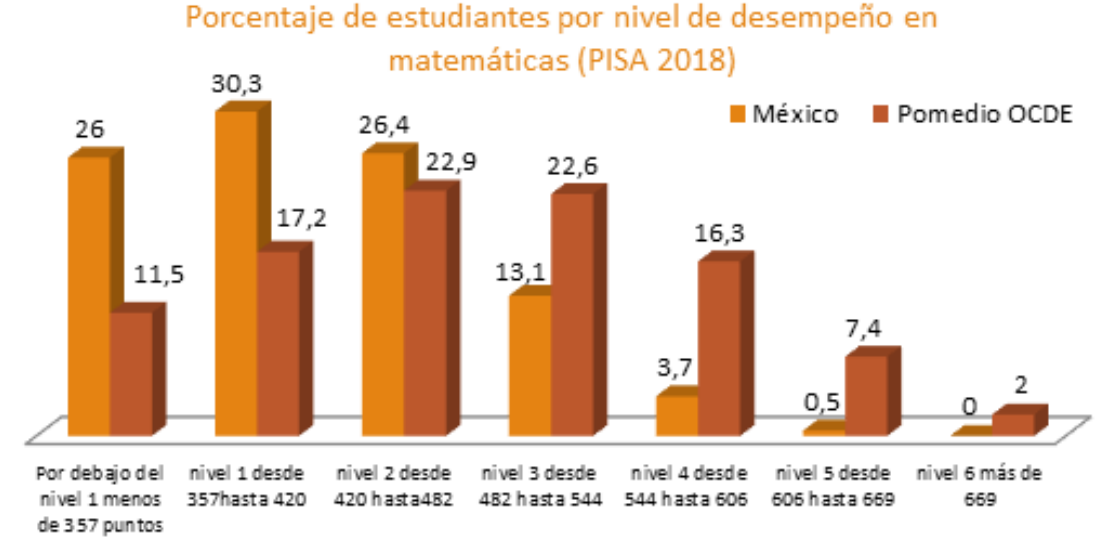

Gráfica 5. Porcentaje de estudiantes por nivel de desempeño en matemáticas. Fuente: OCDE, (2019).

\section{c) Resultados de PISA 2018 en ciencias}

En ciencias, alrededor del $79 \%$ de los estudiantes se concentró entre el nivel 1 y nivel 2 (gráfica 6), lo que implica que los evaluados y evaluadas pueden dar explicaciones científicas simples, partir de la evidencia para explicar situaciones, interpretar literalmente los resultados de una investigación científica, obtener conclusiones basadas en investigaciones sencillas. En contraste, solo el $0.3 \%$ (nivel 5) de los estudiantes puede aplicar los conceptos y el conocimiento de la ciencia a situaciones complejas, pueden comparar, evaluar y explicar la evidencia científica de forma creativa y autónoma, construyen explicaciones basadas en la evidencia científica (OCDE, 2019).

En ciencias el nivel 3 y 4 concentra al $19 \%$ de los estudiantes (gráfica 6). En estos niveles los alumnos pueden seleccionar hechos y conocimientos para explicar fenómenos, hacen deducciones del papel de la ciencia y la tecnología, aplican estrategias sencillas de investigación, 
comunican sus decisiones utilizando el conocimiento y la evidencia de la ciencia, seleccionan e integran a sus explicaciones la mirada de diferentes disciplinas (OCDE, 2019).

\section{Porcentaje de estudiantes por nivel de desempeño en ciencias}

(PISA 2018)

México $n$ Promedio OCDE

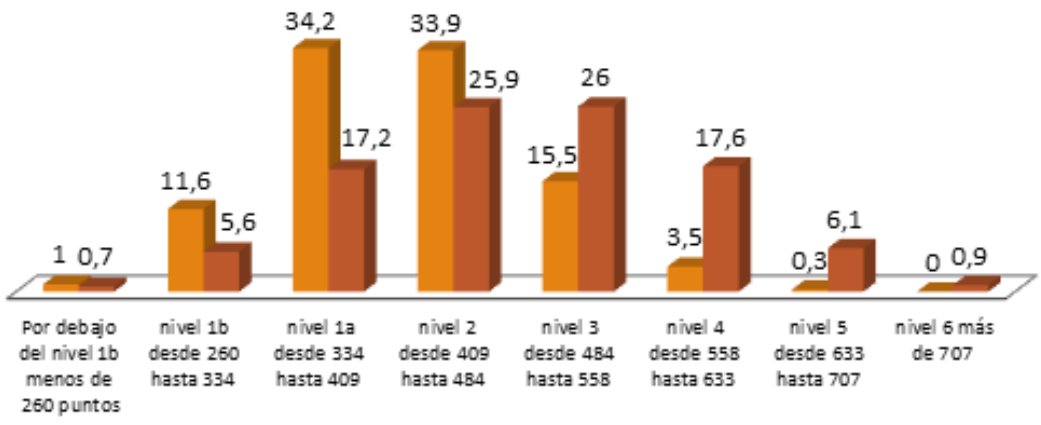

Gráfica 6. Porcentaje de estudiantes por nivel de desempeño en ciencias.

Fuente: OCDE, (2019).

Una vez que se tiene una caracterización de los resultados de la prueba PISA en lectura, matemáticas y ciencia, se pasará al siguiente apartado, el cual relacionan estos indicadores con la política de evaluación al ingreso al servicio educativo durante la administración de gobierno (2012-2018).

\section{La política de ingreso al servicio educativo y su relación con el nivel de rendimiento en la prueba PISA}

La reforma educativa de 2013 ponderó diversas acciones con miras hacia la calidad educativa, en la constitución política de los Estados Unidos Mexicanos así quedó plasmado:

El estado garantizará la calidad en la educación obligatoria de manera que los materiales y métodos educativos, la organización escolar, la infraestructura educativa y la idoneidad de los docentes y los directivos garanticen el máximo logro de aprendizaje de los educandos (DOF, 2013, p. 1).

En septiembre de ese mismo año se promulgó la Ley General del Servicio Profesional Docente (LGSPD), con la finalidad de garantizar la evaluación docente y cumplir con el reto de la calidad de la educación. La política de la evaluación se estableció como un canal de comunicación que pretendía cumplir con las necesidades de ese momento: la calidad de la 
educación a partir de captar a los mejores docentes y mejorar el logro de los aprendizajes de los educandos. La LGSPD regula cuatro aspectos en el ámbito laboral de los docentes de educación básica: el ingreso, la promoción, la permanencia y el reconocimiento, lo que se le llama carrera docente (Murillo, 2007; Cuenca, 2015; Cordero y González 2016; Cuevas y Rangel 2019).

La política de ingreso a la docencia con la reforma educativa de 2013 dibujó, en apariencia, un ingreso al servicio educativo más sistemático y transparente ${ }^{1}$. En este sentido el sistema de evaluación como canal de comunicación se convirtió en un sistema de regulación dirigido a resultados específicos. La evaluación se convirtió en el mecanismo para intentar captar a los mejores docentes que desean ingresar al sistema educativo nacional y terminar con la corrupción en la asignación de plazas docentes (Ornelas, 2012; INEE, 2016). La política de la meritocracia se consolidó como la única vía para ingresar a la docencia en México (así al menos lo referían las autoridades educativas y el ex presidente de México) y en otras regiones del mundo, dejando a un lado aquella que pondera la antigüedad en el servicio educativo y la acumulación de diplomas y certificaciones (Cuenca, 2015; Murillo 2007; Vaillant, 2009; y Cuevas y Rangel, 2019).

La LGSPD estableció en el Marco General de la Calidad de la Educación los perfiles, parámetros e indicadores que iban a servir como referentes en los concursos de oposición para la evaluación docente (LGSPD, 2013). Los perfiles son definiciones a priori de lo que se considera un buen desempeño docente (Cuenca, 2015).

El ingreso al Servicio Profesional Docente (SPD) fue un concurso de oposición abierta, mediante el cual se define si un docente es o no idóneo para cumplir la función docente. Al candidato se le aplicaban dos instrumentos de evaluación: 1) Examen nacional de conocimientos y habilidades para la práctica docente y 2) Examen nacional de habilidades intelectuales y responsabilidades ético-profesionales.

Es importante referir que la profesionalización de la carrera docente no sólo tiende a mejorar el perfil de los que se integran al servicio educativo, también incide en el aprendizaje de los alumnos. En ese sentido, un buen docente está asociado a las siguientes características: 1) el nivel de conocimientos, 2) la capacidad para transmitir esos conocimientos y 3) la motivación y compromiso para su labor (Darling-Hammond, 2001; De Hoyos y Estrada, 2018). En las siguientes líneas se va presentar una relación

${ }^{1}$ Antes de la reforma del 2013 el ingreso a la docencia era a través de: a) asignación de plaza inicial, b) la selección libre de personas y c) propuestas del sindicato (Montaño, 2005). 
posible entre los efectos de la LGSPD sobre el perfil de los nuevos docentes de secundaria, para ello se tomará en cuenta el nivel de conocimientos en relación al lenguaje, matemáticas y ciencias. Se hace de esta manera porque la evidencia internacional identifica una relación importante entre los conocimientos de los docentes en las áreas señaladas y los aprendizajes de los alumnos en éstas áreas (Hanushek, Piopiunik y Wiederhold; 2018; De Hoyos y Estrada, 2018).

Los resultados de las evaluaciones del perfil de ingreso al servicio educativo se clasifican en tres niveles de desempeño (I, II, III) que refieren lo que los sustentantes son capaces de hacer y que los ubica en un grupo de desempeño en particular $(A, B, C)$. Cabe señalar que los grupos de desempeño son para los sustentantes con evaluación idónea, los que tienen evaluación no idónea, sólo así son nombrados. La tabla 2 nos señala las descripciones de cada nivel y el del desempeño del grupo:

Tabla 2. Descripción de nivel y desempeño del grupo.

\begin{tabular}{|c|c|c|c|}
\hline Nivel & Descripción & $\begin{array}{c}\text { Grupo de } \\
\text { desempeño }\end{array}$ & Descripción \\
\hline I & $\begin{array}{l}\text { Dominio insuficiente de los conocimientosy } \\
\text { habilidades que se consideran indispensa- } \\
\text { bles para un adecuado desempeño docente }\end{array}$ & $A$ & $\begin{array}{l}\text { En los dos exámenes } \\
\text { obtuvo el nivel de des- } \\
\text { empeño III. }\end{array}$ \\
\hline II & $\begin{array}{l}\text { Dominio suficiente y organizado de los } \\
\text { conocimientos y habilidades que se juzgan } \\
\text { indispensables para un adecuado desem- } \\
\text { peño docente }\end{array}$ & B & $\begin{array}{l}\text { En un examen obtuvo el } \\
\text { nivel de desempeño III } \\
\text { y en el otro el nivel de } \\
\text { desempeño II. }\end{array}$ \\
\hline III & $\begin{array}{l}\text { El sustentante, además de mostrar un } \\
\text { dominio suficiente y organizado de los } \\
\text { conocimientosy habilidades contemplados } \\
\text { en el instrumento, demuestra una amplia } \\
\text { capacidad para utilizarlos en una diversidad } \\
\text { de situaciones didácticas. }\end{array}$ & C & $\begin{array}{l}\text { En los dos exámenes } \\
\text { obtuvo el nivel de des- } \\
\text { empeño II. }\end{array}$ \\
\hline
\end{tabular}

Fuente: SPD (2014).

Una vez que se tiene la descripción de los niveles y grupos de desempeño. Se presentan las siguientes gráficas que tiene que ver con los resultados de evaluación que obtuvieron los sustentantes a ingresar al servicio educativo en la función de docente a nivel secundaria en las asignaturas de la enseñanza del Español (gráfica 7), Matemáticas (gráfica 8) y Ciencias que considera Biología (B), Física (F) y Química (Q) (gráfica 9). 
Lo que las gráficas presentan en relación al desempeño que lo sustentantes obtienen en las pruebas para ingresar al servicio educativo es una mejora gradual, quizá mínima, pero importante, en el sentido que el servicio profesional como dispositivo atrae a docentes con mejores conocimientos y habilidades para el ejercicio de la docencia, según las pruebas estandarizadas.

Por ejemplo, en español, el grupo A incrementó el porcentaje de sustentantes de 2014 a 2017 en un $6.5 \%$. En matemáticas, el mismo grupo y en el mismo periodo incrementó $6.2 \%$. En ciencias, en el caso de biología, se tuvo un incremento del $5.9 \%$, en física un incremento del $7.4 \%$ y en química un incremento del $2.9 \%$. Cabe señalar que en el área de ciencias hubo un decremento en el 2017 en el porcentaje de sustentantes en relación al constante incremento de los años anteriores.

Porcentaje de sustentantes por grupos de desempeño en Español

\begin{tabular}{|r|r|c|c|}
\hline & \\
\hline
\end{tabular}

Gráfica 7. Porcentaje de sustentantes por grupos de desempeño en español. Fuente: SPD (2014; 2015; 2016; 2017).

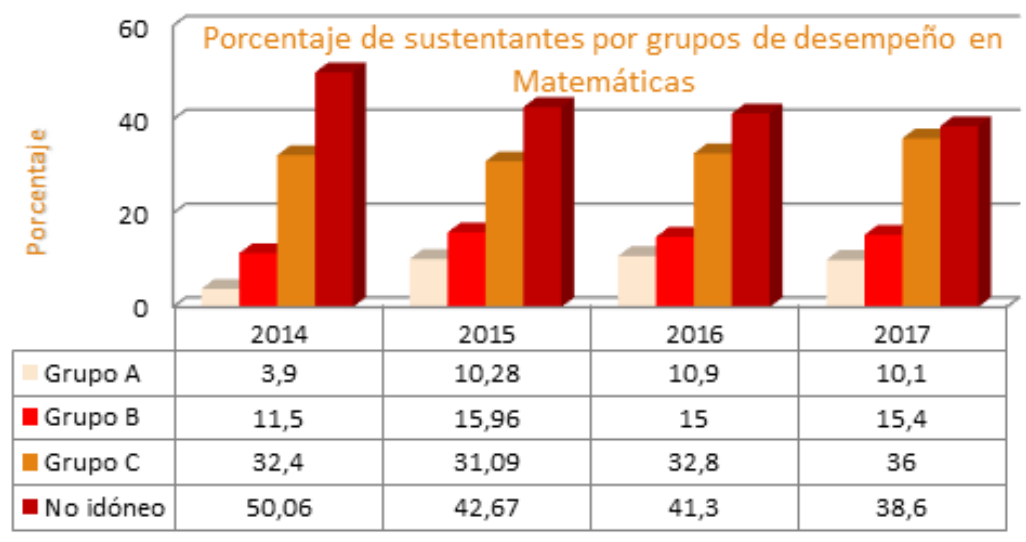


Gráfica 8. Porcentaje de sustentantes por grupos de desempeño en matemáticas. Fuente: SPD $(2014 ; 2015 ; 2016 ; 2017)$.

Los resultados descritos se pueden relacionar con los resultados de PISA 2015 y 2018, puesto que es el periodo cuando ingresan al servicio educativo los docentes evaluados. Por ejemplo, en el área de lectura, se presentó un crecimiento del $0.5 \%$ de estudiantes que logran ubicarse en el nivel 50 superior. En matemáticas y ciencias hay un crecimiento del $0.2 \%$ (tabla 3 ).

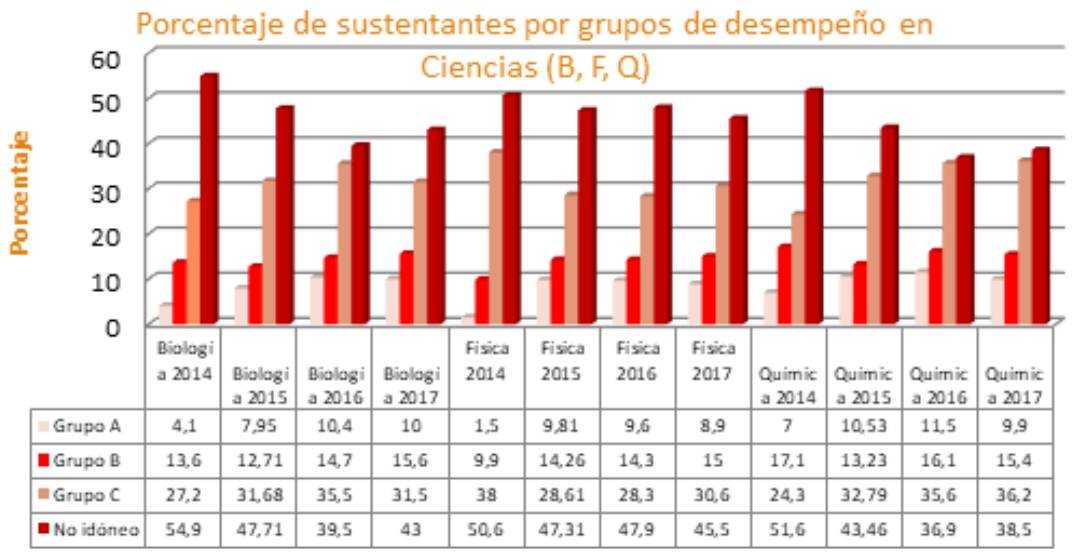

Gráfica 9. Porcentaje de sustentantes por grupos de desempeño en ciencias.

Fuente: SPD $(2014 ; 2015 ; 2016 ; 2017)$.

Tabla 3. Porcentaje de alumnos de alto rendimiento.

\begin{tabular}{lcc}
\hline \multicolumn{1}{c}{ Competencia evaluada } & Nivel 5 o superior PISA & Nivel 5 o superior PISA \\
& $2015(\%)$ & $2018(\%)$ \\
\hline Lectura & 0.3 & 0.8 \\
Matemáticas & 0.3 & 0.5 \\
Ciencias & 0.1 & 0.3 \\
\hline
\end{tabular}

Fuente: OCDE (2019).

Así como se presentó un incremento en el nivel de rendimiento más alto tanto en el desempeño de los docentes de nuevo ingreso al servicio educativo como de los alumnos que presentan la prueba PISA. También hay una disminución en porcentaje en el rendimiento más bajo, excepto en los resultados de lectura que se obtienen por los alumnos (tabla 4).

Por ejemplo, el porcentaje de alumnos que obtienen un nivel de rendimiento por debajo del nivel 2 en lectura incrementó en 3\% en PISA 2018 en comparación con 2015. En la competencia de matemáticas se presentó 
un decremento del $0.4 \%$ y en ciencias disminuyó en $1 \%$. Es decir, un menor número de estudiantes se ubicó en los niveles más bajos de rendimiento en matemáticas y ciencias.

Tabla 4. Porcentaje de alumnos de bajo rendimiento.

\begin{tabular}{lll}
\hline Competencia evaluada & $\begin{array}{l}\text { Por debajo del nivel 2 PISA } \\
\text { Por debajo del nivel 2 PISA } \\
\end{array}$ 2015 (\%) $(\%)$ \\
\hline Lectura & 41.7 & 44.7 \\
Matemáticas & 56.6 & 56.2 \\
Ciencias & 47.8 & 46.8
\end{tabular}

Fuente: OCDE (2019).

Si bien faltarían factores para poder determinar una relación más sistemática entre los resultados que los docentes de nuevo ingreso al servicio docente con los logros de aprendizaje que los alumnos alcanzan en los resultados PISA, es un hecho que el sistema educativo mexicano a partir de la evaluación docente, presentó una tendencia hacia la mejora en los resultados en las pruebas estandarizadas de docentes como de alumnos en las competencias de lectura, matemáticas y ciencias. Incluso, el incremento gradual mínimo en los logros de aprendizajes de docentes y alumnos, puede estar asociado, precisamente, con los criterios de ingreso que se establecen a partir de la creación del SPD. Lo que se puede advertir es que el SDP fue un dispositivo con impacto en la tendencia a la mejora de los resultados y que posiblemente podía ser un camino importante en aras a la calidad educativa. La política de la evaluación que se implementó en México presenta una tendencia positiva en la calidad educativa de la nación (Estrada, 2019).

A pesar de que la política de evaluación fue una iniciativa importante para atraer y captar a los mejores docentes, hubo ciertas cuestiones que probablemente influyeron en que la evaluación docente como canal de comunicación y el SPD como dispositivo no se desarrollara en las mejores condiciones:

1. El ingreso al servicio docente siguió operando a través de usos y costumbres diferentes al mérito (Backhoff, 2017). Es importante mencionar que el sindicato, aun con acotamiento de poder y maniobra, sigue en estas prácticas. El hecho de que el gobierno haya centralizado ciertas decisiones, no implica que la actuación del sindicato se haya aniquilado; posiblemente, tomó otro lugar y se valió de diferentes mecanismos para hacerse presente.

2. La falta de información acerca de los docentes del país y las condiciones en las que trabajan no se conocen con claridad. El Sistema de Información y de Gestión Educativa (SIGED) no cuenta de la información clara y sistemática de los docentes, 
no se logró captar la información del 15.7\% del personal (México Evalúa, 2014). Aunque la tarea se le encomendó no pudo recabar los datos, todavía hay incertidumbre y un sistema de información que no se acaba de completar, que tiene problemas, o que por lo menos, ello parece manifestar. Al no existir datos transparentes en torno a los docentes, era muy probable y factible que el número de plazas u horas que ofrecían las diversas entidades para los aspirantes tuvieran ciertas variaciones. Es decir, las autoridades pueden ofertar cierto número de plazas u horas que no corresponde con las vacantes que existen en los recintos escolares; habría que revirar a algunas convocatorias que se emiten de las entidades, a través de la página del Servicio Profesional Docente (SPD). Hay infinidad de centros escolares que no cuentan con la plantilla docente completa a pesar de que hay una lista de docentes que, de acuerdo al mérito, están en derecho de estarlo. Al no haber información sistemática, precisa y transparente, se posibilita el flujo de los mecanismos discrecionales (Fernández, 2018).

3. A pesar de que la LGSPD establece el sistema de tutorías para los docentes de nuevo ingreso durante sus primeros dos años de docencia, con la finalidad de que el asesor pudiera apoyar al docente con sus fortalezas y debilidades en el ejercicio de la docencia. Sin embargo, la cobertura del sistema de tutores fue insuficiente. Según el INEE sólo el 58\% de los docentes de nuevo ingreso habían recibido tutorías en el ciclo escolar 2014-2015 (INEE, 2017). El problema de la asignación de tutores estuvo relacionado a falta de presupuesto, comunicación y coordinación entre autoridades federales y estatales (Hernández, 2015) y porque las evaluaciones de los docentes de nuevo ingreso llegaban a destiempo, lo que dificultó la planeación de las tutorías (Fernández, 2018.)

4. Con la reforma educativa que se impulsó en 2013 , la precarización salarial es notable, y es más "visible" por el poco número de horas que se les asigna a los docentes normalistas de nuevo ingreso, lo que alimenta las condiciones laborales inciertas (Compañ, 2018). Los docentes reciben un número de horas inferior a lo que se les otorgaba anteriormente. En la década de los noventa se les otorgaba a los egresados de las escuelas normales un mínimo de 19 horas, lo que les permitía tener un salario más elevado. Actualmente, hay docentes con 5 horas y un salario insuficiente. El número de horas que se les otorga a los docentes es variable; depende de la especialidad y el número 
de grupos existentes en el centro escolar, lo que repercute en su ejercicio docente (Compañ, 2018)

La política de evaluación docente fue un acierto importante de la administración de gobierno, que se asoció, según la evidencia, con los logros de aprendizaje de los estudiantes. Sin embargo, las condiciones laborales de los docentes no mejoraron. Se captó a los mejores docentes, pero no se asoció ello con incentivos salariales o prestaciones favorables. Lo que se tradujo en contenido importante pero un proceso opaco.

\section{Comentarios finales}

Si bien, la política de evaluación al ingreso al servicio educativo como canal de comunicación y la creación del SPD como dispositivo en la administración de gobierno anterior, no resolvió los rezagos en materia educativa, sí sentó las bases que posibilitaran una transformación en el sistema educativo nacional en aras a la calidad educativa.

La política de la evaluación docente no sólo se estableció como un mecanismo para acabar con la corrupción en la asignación de plazas docentes, incluso, no se logró en su totalidad, sino como un mecanismo de regulación que pudiera captar a los mejores docentes para incorporarlos al servicio educativo y de esa manera elevar el nivel de rendimiento de los alumnos. A partir de la creación del SPD se percibe un incremento gradual mínimo en el rendimiento de los docentes de educación secundaria, que ingresan al sistema educativo nacional en el área de español, matemáticas y ciencias y, un avance en los logros de aprendizaje en las competencias evaluadas en PISA.

El hecho de que un canal de comunicación con impacto sustantivo, como la evaluación al ingreso a la docencia, no haya tenido mayor éxito y quizá más impacto en los logros de aprendizaje, se debe a que el dispositivo, en este caso el SPD, no pudo tener un control sistemático de ciertos procesos y resultados, cuestión importante en la implementación de un dispositivo (Rivas, 2015). La falta de coordinación y comunicación entre autoridades federales estatales, las limitaciones del presupuesto para la asignación de tutores que coadyuvaran a la formación de los docentes de nuevo ingreso, la falta de planeación para el trabajo con los tutorados y la participación de actores como la CNTE, que se resistieron y se opusieron a los procesos de evaluación, fueron elementos que no ayudaron a que la evaluación al ingreso a la docencia se pudiera sentar sobre condiciones más favorables y sólidas. 
Asegurar la calidad de la educación en términos de captar a los mejores docentes y mejorar los logros de aprendizaje de los alumnos requiere: 1) un presupuesto destinado para la formación de los docentes de nuevo ingreso, 2) realizar estudios más sistemáticos y con mayores elementos que permitan establecer la relación entre los logros de aprendizaje de los alumnos y la evaluación docente, 3) mejorar las condiciones laborales de los docentes, 4) mayor coordinación entre gobierno federal y gobierno estatal, 5) tener la información clara y precisa de los docentes. Se necesitan dispositivos de política educativa que se les dé seguimiento en términos de evaluarlos y focalizarlos. La política educativa tiene que gozar de cierta estabilidad, coherencia, coordinación y buscar el bienestar general, si de verdad se aspira a la calidad educativa. De lo contrario, la política educativa presentará contenidos interesantes pero se desarrollará bajo procesos opacos, irregulares e improvisados.

Lamentablemente, todo lo anterior, parece no estar en la agenda de la administración de gobierno actual. Por ejemplo, hasta ahora, la evaluación al ingreso a la docencia no se lleva a cabo, lo que puede implicar que la probabilidad de que los logros de aprendizaje mejoren se va más distante, además que lo que sí se mira próximo es el regreso a las prácticas clientelares de asignación de plazas docentes.

\section{Referencias}

Backhoff,E. (8 de agosto de 2017). Terminó la injusta y opaca asignación de plazas para maestros. La jornada. Recuperado de https://bit.ly/30iPqdo

Backhoff, E. ( 9 de diciembre de 2019). México en PISA 2018, Nexos. Recuperado de https:// bit.ly/2GfryR3

Backhoff, E; Bouzas, A. Contreras, C. Hernández, E. y García, M. (2007). Factores escolares y aprendizaje en México. México: INEE.

Bernstein, B. (1998). Pedagogía, control simbólico e identidad. Morata: Madrid.

Blanco, E. (2012). El reciclaje de la desigualdad: exclusiones educativas en América Latina. En Puchet, M. et al.(Eds.). América Latina en los albores del siglo XX: 2. Aspectos sociales y políticos. (pp. 63-94). México: FLACSO.

CEPALSTAT (2020). Asistencia escolar de ambos sexos por quintiles de ingreso per cápita del hogar, según grupos de edad y área geográfica. Estadísticas e indicadores sociales, CEPAL. Recuperado en https://bit.ly/3kTtTzQ

Compañ, J. ( 22 de agosto de 2018 ). La política de ingreso a la docencia: aciertos y desafíos. Nexos. Recuperado de https://bit.ly/2GrvduL 
Cordero, G. y González, C. (2016). Análisis del modelo de evaluación del desempeño docente en el marco de la reforma educativa Mexicana. Archivos Analíticos de Políticas Educativas. (24) pp.1-26.

Cuenca, R. (2015). Las carreras docentes en América Latina: la acción meritocrática para el desarrollo profesional. Chile: OREALC-UNESCO.

Cuevas, Y. y Rangel, K. (2019). Análisis de la carrera docente en la educación primaria en México: Entre el credencialismo y la meritocracia. Archivos Analíticos de Políticas Educativas. 27(44). http://dx.doi.org/10.14507/epaa.27.4323

Darling-Hammond, L. (2001). El derecho de aprender. Crear buenas escuelas para todos. España: Ariel.

De Hoyos, R. y Estrada, R. (2018). ¿Los docentes mejoraron?¡Sí!. Nexos. Recuperado de https:// bit.ly/3019WKo

Diario Oficial de la Federación (DOF) (2013). Decreto por el que se declara deformado el artículo 3 de la Constitución Política de los Estados Unidos Mexicanos. Recuperado de http://www.dof.gob.mx

Estrada, R. (2009) Reglas versus discreción en el servicio público: contratación de docentes en México. Diario de economía laboral, (3)7 (2), 545-579.

Fernández, M. (2018). Construir una educación inclusiva, equitativa y de calidad. Ciudad de México: México Evalúa.

Hanushek, Piopiunik y Wiederhold (2018). The value of smarter teachers: international evidence on teacher cognitive skills and student performance. NBER Working Paper Series 20727. Cambridge: MA.

Hernández, L. (5 de septiembre de 2015). Destina SEP sólo 200 pesos a capacitación docente de maestros. Excélsior. Recuperado de https://bit.ly/2Sanx2C

Hunter, I. (1998). Repensar la escuela. Subjetividad, burocracia y crítica. Barcelona: Pomares.

Instituto Nacional para la Evaluación Educativa (INEE) (2016). México en PISA 2015. México: INEE.

Instituto Nacional para la Evaluación de la Educación (INEE) (2017). Las tutorías como estrategia de inserción a la docencia. La educación obligatoria en México. Ciudad de México: INEE.

Ley General para el Servicio Profesional Docente (2013). México: Gobierno de México.

Martínez, F. (2012). El futuro de la educación, Sinéctica, 40, 1-11. Recuperado de https:// bit.ly/3ib1140

Martínez, F. (2016). Impacto de las pruebas en gran escala en contextos de débil tradición técnica: Experiencia de México y el Grupo Iberoamericano de PISA. Revista Electrónica de Investigación y Evaluación Educativa, 22(1). Recuperado de https://bit.ly/3I2NMoq

Martínez, F. (1 de marzo de 2017). Hay realmente una catástrofe educativa en México, Nexos. Recuperado de https://bit.ly/3cJ6u14

México Evalúa (2014). Censo Educativo. Radiografía del dispendio presupuestal. Ciudad de México: México Evalúa. 
Montaño, L. (2005). La formación del docente actual de las escuelas secundarias generales en el Distrito Federal. Caminos para la docencia. Tesis de Maestría en Desarrollo Educativo. México. Universidad Pedagógica Nacional.

Muñoz, C. (2005). Análisis de los resultados de México en el PISA 2003: una oportunidad para las políticas públicas, Perfiles latinoamericanos, 13(26), 83-107.

Muñoz, C. (2009). Construcción del conocimiento sobre la etiología del rezago educativo y sus implicaciones para la orientación de las políticas públicas: la experiencia de México. Revista Iberoamericana sobre Calidad, Eficacia y Cambio en Educación (7) (4) 28-45.

Murillo, J. (2007). Evaluación del desempeño y carrera profesional docente. Un estudio comparado entre 50 países de América y Europa. Chile: OREALC-UNESCO.

Organización para la Cooperación y el Desarrollo Económico (OCDE) (2017). El programa PISA de la OCDE. Qué es y para qué sirve. París: OCDE. Recuperado de https://bit.ly/3igNyYT

Organización para la Cooperación y el Desarrollo Económico (OCDE) (2018). Marco de Evaluación y de Análisis de PISA para el desarrollo. París: OCDE.

Organización para la Cooperación y el Desarrollo Económico (OCDE) (2019).Programa para la Evaluación Internacional de Alumnos PISA 2018 - Resultados. París: OCDE.

Ornelas, C. (2012). Educación, colonización y rebeldía: La herencia del pacto Calderón-Gordillo. México: Siglo XXI.

Pedró, F. y Puig, I. (Coords) (1998). ¿Sirve para algo la Política Educativa? En Las reformas educativas. Una perspectiva política y comparada. Barcelona: Paidós.

Poy, Laura (6 de diciembre de 2016). México, sin avances en matemáticas, lectura y ciencia en una década, La Jornada. Recuperado de https://bit.ly/36laKTh

Rivas, A. (2015). América Latina después de PISA: Lecciones aprendidas de la educación en siete países (2000-2015). Buenos Aires: CIPPEC-Natura-Instituto Natura.

Rodríguez, R. (2005). "México en los resultados PISA 2003. Una interpretación no catastrófica". Revista Mexica de Investigación Educativa, 24(10), 255-266.

Rose, N. (1999). Powers of Freedom: Reframing Political Thought. Cambridge: Cambridge University Press.

Santiago, P., McGregor, I., Nusche, D., Ravela, P. y Toledo, D., (2012) Revisiones de la OCDE sobre la Evaluación en Educación México OCDE. México: INEE SEP.

Scarstacini, C. Spiller, P. y Stein, E. (2010). El juego político en América Latina ¿Cómo se deciden las políticas educativas? Colombia: BID.

Secretaría de Educación Pública (2020). Reporte de indicadores educativos. Indicadores y pronósticos educativos. Recuperado de https://bit.ly/3jguA5P

Vaillant, D. (2009). Políticas de inserción a la docencia en América Latina. La deuda pendiente. Revista del currículum y formación del profesorado, 1(13), 27-41. 
